\title{
The Pisacano Legacy Lives on Through the Scholars
}

The ABFP is securing the future of family practice in the hands of the best and brightest family physicians. Since 1993, the Board's philanthropic Pisacano Leadership Foundation has awarded scholarships to 45 medical students who have shown the highest levels of scholarship, leadership, character, interpersonal skills, and community service. Today, 20 of these Pisacano scholars are practicing physicians, and 25 are attending medical school or are enrolled in family practice residencies across the country. Through their education and achievements, the Pisacano scholars carry on the vision and legacy of Nicholas J. Pisacano, $M D$, the ABFP's first executive director and for whom the foundation is named.

Robert J. Cattoi, the executive director of the Pisacano Leadership Foundation, has worked closely with the scholars during the past 6 years. He states, "Each scholar continues to demonstrate the ideals that made them part of the inaugural group." They are committed to the same principles that Dr. Pisacano once taught: the welfare of the patient is of utmost importance, and physicians should be broadly educated. The scholars constantly strive for excellence in their professional and personal lives.

The following are summaries of the efforts and accomplishments of each member of the first class of Pisacano scholars:

Kirk Bollinger, $M D$ - Since completing residency in June 1998, Dr. Bollinger moved to Cody, Wyoming, and worked in a group setting, practicing the entire breadth of family practice including obstetrics. During this time he was appointed the regional chairman for the Wyoming Academy of Family Practice. In July of this year he made a career change to full-time emergency medicine, which allows him to practice primary care along with acute medicine and trauma, two of his other interests. He instructs other physicians around the state in acute care medicine. Dr. Bollinger was appointed to the Governor's Trauma Council and plays an active role in developing the state's trauma plan. He is actively involved in teaching emergency medical technicians through statewide conventions.
Dr. Bollinger also maintains a visiting faculty position at the University of Wyoming Family Practice Residency Program in Casper, where he teaches once a month and serves as a preceptor.

Kara Cadwallader, MD - Dr. Cadwallader completed her residency at Tacoma Family Medicine and practiced in a semirural setting in Washington for a year. She has recently joined a community-based family practice group in Northern California and continues to practice broad-spectrum family medicine, including procedural and inpatient medicine, surgical obstetrics, and minor surgery. She is committed to women's health and reproductive rights and has worked extensively with Planned Parenthood. Dr. Cadwallader will soon begin teaching and attending part-time at the family practice residency program in Santa Rosa, California. Her future goals include increased involvement with the indigent, Latino health care issues, and developing skills in medical editing and writing. She would eventually like to teach fulltime in a community setting working with both medical students and residents.

Cheng-Chieh Chuang, MD - After he was graduated from Brown University with honors, Dr. Chuang taught in English, Chinese, and Spanish at a New York City public high school before his medical studies at Yale. He also took a year off medical school to work on nutrition education in a housing project in Bridgeport, Conn. In the year since his residency training at Brown University Family Medicine Program, he has been working as a locum tenens physician in medically underserved regions of the country: an agricultural zone in South Carolina, a mill town in Maine, Navajo reservations in the Southwest desert, and run-down urban neighborhoods of Rhode Island. He continues to pursue his interest in watercolor painting. In the past year he raised more than $\$ 5000$ for research and education related to human immunodeficiency virus infection and acquired immunodeficiency syndrome.

Eric Crall, MD - Dr. Crall, a former chief resident at Bayfront Medical Center in St. Peters- 
burg, Florida, currently practices inpatient and outpatient family medicine in a large primary care group in New Port Richey, Fla. He uses an electronic medical record, which facilitates his active participation in clinical research. He serves as a clinical preceptor for third-year medical students from the University of South Florida College of Medicine 2 days each week in his office. The thirdyear students at USF voted Dr. Crall Family Medicine Preceptor of the Year for 1998-99. Dr. Crall, his wife, and 2 children reside outside Tampa.

Kenneth Grimm, MD - Dr. Grimm was graduated with honors from the University of Pennsylvania School of Medicine, where he was active in the Pennsylvania and American Academies. After completing residency at the University of Michigan, he became the assistant program director and site medical director for the Family Practice Residency Center in Belleville, Michigan. His time is divided evenly between patient care and teaching residents and medical students. $\mathrm{He}$ also runs the obstetrics-gynecology and evidence-based medicine curricula at his program. Dr. Grimm has written POEM (patient-oriented evidence that matters) reviews, serves as a peer reviewer for The fournal of Family Practice, and is currently working on a chapter for a family medicine textbook. He has just started a part-time 1-year primary care faculty development fellowship program at the Michigan State University. He and his wife, Michele, have 2 children.

Penny Jeffery, MD - Dr. Jeffery was raised in the small community of Mankato, Kansas. She was graduated with honors from both Friends University in Kansas and the University of Iowa School of Medicine. She was elected into Alpha Omega Alpha and received the Janet $M$. Glasgow Memorial Achievement Citation in medical school, and later was named Teaching Resident of the Year. Today, Dr. Jeffery, her husband, and 2 small children live near Wichita, Kansas, where she works part-time in a family practice group setting. She enjoys the full spectrum of family practice patients and especially loves delivering babies and focusing on women's health. She actively participates in Project Access, a local program for uninsured patients. Dr. Jeffery also teaches part-time at the University of Kansas School of Medicine in Wichita, where she supervises third-year students in their standardized patient program and assists with continuing medical education courses for statewide preceptors.
Linda M. C. Lou, MD, SM - Dr. Lou was graduated with high honors from Rice University and followed that with 1 year as a Vista volunteer. She received her master's degree in Health Policy and Management from Harvard University. While working on policy issues related to community health centers, she became interested in becoming a physician for the medically underserved. As a student at the University of Washington School of Medicine, she first spent some time at the International District Community Health Center (IDCHC), caring for Seattle's Asian immigrant community. After completing her family practice residency, she returned to IDCHC as a family physician. Fluent in Mandarin, she now cares for mostly monolingual Chinese patients. With Spanish language skills as well, she also maintains her interest in serving Latino communities through an obstetric and inpatient coverage arrangement with two other community health centers in Seattle.

Katrina Posta, MD - Dr. Posta was graduated magna cum laude from Harvard University and received her medical degree from University of California, Los Angeles, School of Medicine. She completed her residency training at Santa MonicaUCLA Medical Center and then accepted a position as assistant clinical professor at UCLA. Most of her practice involves direct patient care at her office at UCLA Medical Group, Malibu, where she treats the full range of family practice medical problems, including obstetrics and gynecology. Dr. Posta also spends a considerable amount of time teaching residents at Santa Monica UCLA Medical Center and teaching medical students in her office. She has been working on developing more effective patient education materials and is in the process of submitting an article for publication on this topic. She has also been involved with a group of physicians working to update and modify primary care network and utilization review process at UCLA.

Jamie Reedy, MD, MPH - Dr. Reedy was graduated from the University of Medicine and Dentistry of New Jersey, Robert Wood Johnson Medical School, where she is now an instructor in the Department of Family Medicine. In addition to acting as a preceptor to medical students, she has an active pediatric and women's health practice. She directs a publicly funded pediatric clinic for uninsured children. Dr. Reedy is applying for her masters in public health degree in health policy from Johns Hopkins School of Public Health in her 
current position as the health policy advisor to the New Jersey Senate Health Committee. She also serves as the program director of the Pisacano Leadership Foundation, where she is able to develop leadership programs for the scholars.

David Turner, MD - Dr. Turner was graduated with honors from the Dartmouth-Brown Program in Medicine. During his training he has worked in clinics in Tanzania; Saigon, Vietnam; Bethel, Alaska; and urban areas in Chicago. Dr. Turner completed residency at Tacoma Family Medicine and a 1-year fellowship in rural and surgical obstetrics, both in Washington. His National Health Service Corps scholarship commitment has allowed him and his wife, who is also a family physician, to join a new clinic in rural Hancock, New York, where he will pursue his goals of providing community-oriented primary care to an underserved population and empowering patients to take charge of their health.

Mr. Cattoi concludes, "Dr. Pisacano's legacy is thriving, and the future of family practice is brighter than ever. The ABFP is making a wise investment by charging the Pisacano Leadership Foundation to develop a nucleus of leaders who will guide the Board and the specialty in the future. Dr. Pisacano would be proud of these young men and women." 